\title{
Influence of post curing on GFRP hybrid composite
}

\author{
Vithal Rao Chavan ${ }^{1 *}$, K. R. Dinesh ${ }^{2}$, K. Veeresh ${ }^{1}$, Veerabhadrappa Algur ${ }^{3}$ and Manjunath \\ Shettar ${ }^{4}$ \\ ${ }^{1}$ Department of Mechanical Engineering, Rao Bahadur Y. Mahabaleshwarappa Engineering College, \\ Bellary, India. \\ ${ }^{2}$ Department of Mechanical Engineering, Government Engineering College, Raichur, India. \\ ${ }^{3}$ Department of Industrial and Production Engineering, Rao Bahadur Y. Mahabaleshwarappa \\ Engineering College, Bellary, India. \\ ${ }^{4}$ Department of Mechanical and Manufacturing Engineering, Manipal Institute of Technology, \\ Manipal Academy of Higher Education, Manipal, India.
}

\begin{abstract}
Composite materials for the most part depicted as the mixes of two or more materials that outcome in the unmistakable properties than that of guard materials. Fibre strengthened plastics have been all around utilized for get-together flying machine and transport key parts as a delayed consequence of their specific mechanical and physical properties, for example, high particular quality and high particular robustness. Another pertinent application for fibre maintained polymeric composites (particularly glass fibre strengthened plastics) is in the electronic business, in which they are utilized for passing on printed wiring sheets. The utilization of polymer composite materials is winding up being powerfully essential. The present work delineates the change and mechanical portrayal of new polymer composites including glass fibre fortress, epoxy and maple cellulose fibre. The starting late made composites are delineated for their mechanical properties. The composite spreads were set up by utilizing hand layup framework. The experiments were conducted on and studied the effect of post curing on hybrid composites. The result reveals that the samples only with natural fibre have more promising results compared with synthetic fibre. The synthetic fibres get wrinkled due to post curing were as no such visuals in the natural fibres.
\end{abstract}

Key words: Post curing, GFRP, Cellulose fibre, Tensile, Impact, Hardness.

\section{Introduction}

Composite materials are defined as "a combination of two or more materials that results in better properties than those of the individual components used alone". These materials have high strength and stiffness tailored with low density, as compared to the conservative

\footnotetext{
* Corresponding author: nrvithalchauhan@gmail.com
} 
metals. Polymer matrix composites (PMCs) are viscoelastic materials. Mechanical properties of PMCs are significantly influenced by heat i.e., variation in temperature. The PMCs are mostly used in the area like aerospace, automobiles and marine applications [1].

Curing is an irreversible reaction where chemical covalent cross-links are formed whichare thermally and mechanically stable. The curing process plays a vital role to achieve the end mechanical properties and chemical resistance of PMCs. For the fabrication of PMCs, resin and curing agents (hardener) with proper ratio are used. During crosslinking, the stateof matrix changes from liquid to gel and then transforms into solid. Curing can be done at room temperature as well as at elevated temperature [2].

\section{Literature review}

Cagri Uzay et al., worked on the post cure heat treatment on the impact toughness and tensile properties of fibre reinforced composites. The laminates were prepared by utilizing the hand layup vacuum bag moulding of woven carbon and glass fibre fabric plies. At three distinct temperature, the post curing was done for one hour i.e. $25,62.5$ and $100^{\circ} \mathrm{C}$. The impact (charpy) and tensile test were conducted along with the statistical analysis to know the effect of post curing and different type hybrid plies. The results reviled that post curing has positive effect on energy absorption capacity and tensile properties of FRP [3].

As the operating temperature varies the characteristics of FRP got altered, especially impact behaviour, under various operating temperature ranges Viz., -70 to $180{ }^{\circ} \mathrm{C}$ [4], -75 to $75{ }^{\circ} \mathrm{C}$ [5] and -75 to $25^{\circ} \mathrm{C}$ [6]. The result stated that FRP made up of carbon fibre were highly responsive to the impact loads due to its behaviour of brittleness, therefore both toughness and impact was directly proportional to the temperature.

Gonzalez et al., investigated the impact behaviour of PEEK and its short carbon fibre reinforced composite (SCFR PEEK) at low temperatures. The brittleness of PEEK and SCFR, PEEK composites at low temperatures could restrict the application of this composite in aeronautical applications [6].

Aktaş and Karakuzu, investigated on the properties such as tensile, compression and shear, of unidirectional glass/epoxy composite plies under distinct temperature from 20 to $100^{\circ} \mathrm{C}$ and the results showed that, the fibre direction influenced decrease in tensile strength and modulus of elasticity (after 60 and $80^{\circ} \mathrm{C}$ ). As the temperature increased the rigidity and strength of composites were decreased [7].

A similar study was made by Cao et al. [8] and tested the carbon FRP from 16 to $200^{\circ} \mathrm{C}$. The result showed that, the tensile strength decreased significantly with increasing temperature and remained almost stable after the polymer exceeds its glass transition temperature. On the other side, at cryogenic temperatures, it was shown that CFRP composites had better tensile properties [9]. The tensile properties of FRP composites have also been affected by curing temperature used during fabrication of composite materials. Generally, the specimens have been cured at room temperature. However, the increase in curing temperature improves the mechanical properties compared to curing at room temperature $[10,11]$. As the post-curing process improves mechanical properties of the composites and enhances their chemical durability and heat resistance [12], post-curing heat treatment processes have been studied for composites and its adhesives [13].

Hiremath et al. determined the optimum post-curing temperature for epoxy/alumina polymer nanocomposite in order to obtain better viscoelastic and flexural properties [14]. Similarly, Kumar et al. determined both optimum post-curing temperature and time for interlaminar shear strength (ILSS) and the corresponding glass temperature (Tg) of glass 
FRP composites. While the curing temperature during fabrication and the effect of various operating temperature conditions have already been investigated, and discussed, the knowledge about post-curing effect on impact and tensile strength of FRP composites is limited and further studies are needed. As it is stated in the literature, without post-curing heat treatment process, the polymer matrix is not strong enough and the failure of composites under loading mostly occurs due to the crushing of polymer matrix [15].

\section{Methodology}

Design and modification of polymer matrix composite:

Based on the composite design the specimen has to be fabricated by using hand lay-up technique. The proper volume fraction of fibres, epoxy, and cellulose fibres is to be controlled [16]. The laminates are cured for a period of $12 \mathrm{hr}$. The sample is cut to a required size for the tests [17]. And post cured the samples for $1 \mathrm{hr}$ by varying the temperature.

\subsection{Specimen Preparation}

The materials used for the specimen preparation were E-glass fibre plain woven mat (200gsm) and epoxy (LAPOX L-12) with hardener (K-6), purchased from ATUL India Ltd, Gujarat, India. The hand layup technique (figure 1) was adopted for specimen preparation. In connection of volume fragment, the estimations were made for $60-40$ (60\% Resin- 40\% Fibre). One filler material i.e. cellulose fibre were added to various mixes by keeping Epoxy rate as continuing $(60 \%)$. Table 1 shows the proportionate of three materials used for laminate preparation.

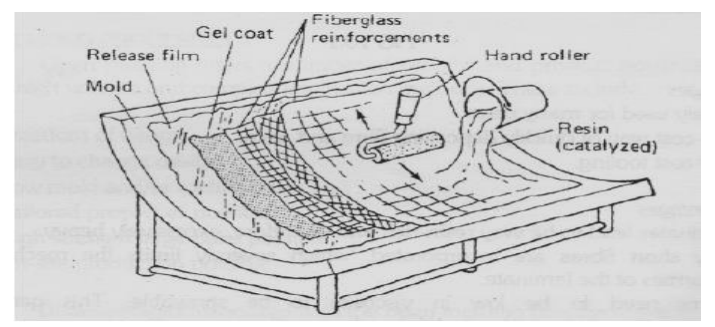

Fig. 1. Hand layup technique

Table 1. Details of Glass/Epoxy and Cellulose fibre Proportions

\begin{tabular}{|c|c|c|c|}
\hline Laminate No & Glass fibre(Wt \%) & Cellulose fibre(Wt \%) & Matrix material (Wt \%) \\
\hline 1 & $35 \%$ & $5 \%$ & $60 \%$ \\
\hline 2 & $30 \%$ & $10 \%$ & $60 \%$ \\
\hline 3 & $25 \%$ & $15 \%$ & $60 \%$ \\
\hline 4 & $20 \%$ & $20 \%$ & $60 \%$ \\
\hline 5 & $5 \%$ & $35 \%$ & $60 \%$ \\
\hline 6 & $0 \%$ & $40 \%$ & $60 \%$ \\
\hline
\end{tabular}

\subsection{Testing of mechanical properties}

- Tensile test is to be conducted as per ASTM D3039 standards.

- Impact test (charpy) ASTM D2344 standards.

- Hardness test ASTM E20-00 standard 
The ultimate tensile strength and percentage of elongation of the composite was studied with varying percentage of reinforcement and filler material and varying the temperature of post curing.

\section{Result and Discussion}

In this study, the tensile, impact test and hardness test were carried out on glass epoxycellulose fibre filled composites, to study the effect of fibre proportionate and post curing of those composites. In this section, experimental result obtained for tensile, impact and hardness tests are widely discussed. The results were analyzed by plotting bar graphs for materials that were having different proportions of cellulose fibre and varying temperature materials.

\subsection{Tensile Test}

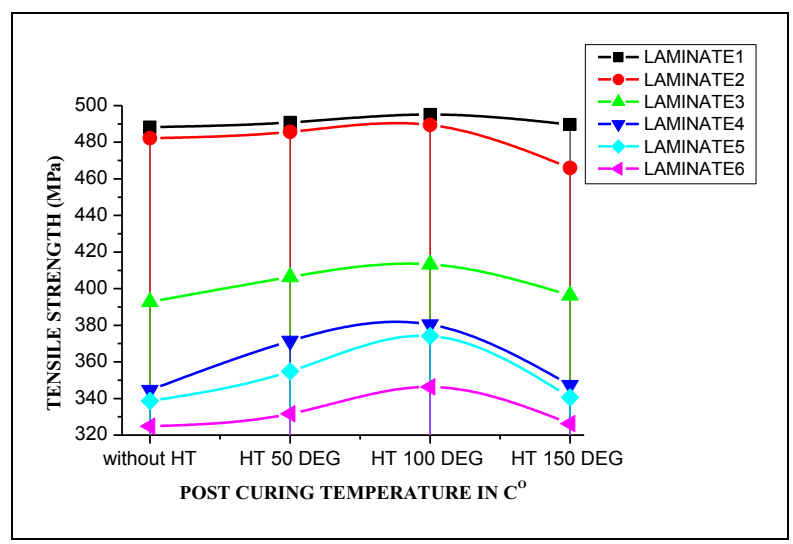

Fig. 2. Comparison of tensile strength

Tensile test was carried out for the different fibre weight percentage of laminates with different post curing temperature viz., 50,100 and $100^{\circ} \mathrm{C}$. Figure 2 shows comparison of tensile strength for the different laminates at different post curing temperature. The result reveals that laminate 1 without post curing i.e. at $5 \mathrm{wt} \%$ of cellulose fibre, $35 \mathrm{wt} \%$ of Eglass fibre and $60 \mathrm{wt} \%$ of epoxy resin, showed the higher tensile strength compared to the other samples. The tensile fracture is due to delamination of the fibres. Delamination of the fibre may be found due to weak bonding between the fibres and resin. The fracture due to delamination of the fibre decreased as the percentage of cellulose fibre is increased because cellulose fibre is laid up along with epoxy as the percentage of cellulose fibre increases Eglass fibre percentage decreases this is done to maintain constant volume of $300 \mathrm{~mm} \times$ $300 \mathrm{~mm} \times 3 \mathrm{~mm}$. However, increase in post curing temperature decreased the strength. The cellulose fibre is having more tendency of getting adhere with resin, as temperature is increased the viscosity got decreased and most of the resin is been consumed with cellulose fibre, hence there is decrease in strength. 


\subsection{Impact Test}

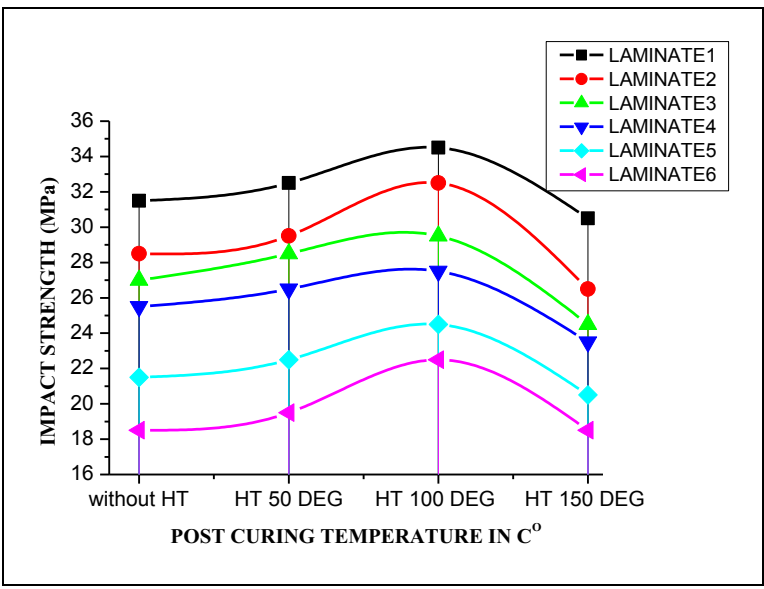

Fig. 3. Comparison of impact strength

As shown in figure 3 , laminate 1 with post curing at $100^{\circ} \mathrm{C}$ had higher impact strength compared to the other samples. The test reveals that, the increase in the impact strength is due to the proper wettability of the fibre with resin. The decrease in viscosity of resin and overheating at higher temperature leads to reduction in its impact strength. All other samples are follows the same pattern as shown figure i.e., increase the impact strength up to $100^{\circ} \mathrm{C}$ of post curing, but drastically reduces at $150^{\circ} \mathrm{C}$ of post curing. This is because the fracture process of fibres is generally accompanied by the damage of chemical bond, intermolecular slip and the weakening of van der Waals force, etc. Heating will undoubtedly weaken the chemical bond and van der Waals force and then lower the strength of fibres. Also, increase the in cellulose fibre percentage reduces the impact strength, it might be due to agglomeration of fibre.

\subsection{Hardness Test}

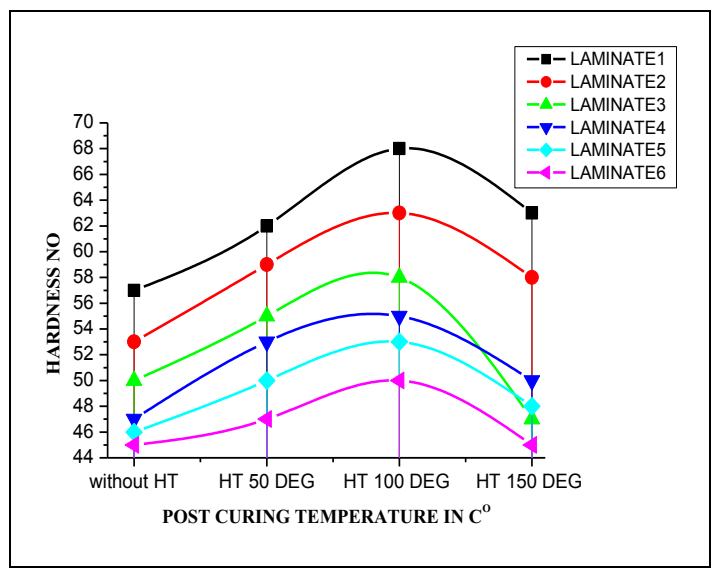

Fig. 4. Comparison of hardness number

As shown in figure 4 , all laminates, at $100^{\circ} \mathrm{C}$ post curing exhibits higher hardness value compared to other samples. The post curing results in increase in the bonding between fibres and resin, due to increase in cross-linking and stacking, which reduces the movement 
of polymer molecules and making it to become more resistant to the penetration of indenter. The overheating at $150^{\circ} \mathrm{C}$ resulted in decrease in hardness value due to degradation the matrix materials, warp, etc.

\section{Conclusions}

All composite with filler material exhibited satisfactory mechanical properties than unfilled composites. Composites showed failure due to delamination as the filler percentage increases this may be because weak bonding between the fibres. Hence to strengthen the bonding between the synthetic and natural fibres the post curing is adopted. The post cured samples of both synthetic and natural fibres give the better results compared with the after and before post curing.

- The Tensile Strength of post cured samples at $100^{\circ} \mathrm{C}$ for 1 hour of $40 \mathrm{Wt} \%$ of cellulose fiber and $60 \mathrm{Wt} \%$ of resin sample had increased with $6.74 \%, 35 \mathrm{Wt} \%$ E-glass fiber , $5 \mathrm{Wt} \%$ of Cellulose fiber and $60 \%$ of resin sample had increased with $1.38 \%, 20 \mathrm{Wt} \%$ E-glass fiber ,20Wt $\%$ of Cellulose fiber and $60 \%$ of resin sample had increased with $9.42 \%, 5 \mathrm{Wt} \%$ E-glass fiber, $35 \mathrm{Wt} \%$ of Cellulose fiber and $60 \%$ of resin sample had increased with $7.28 \%$, when compared with, samples without post curing.

- The Impact Strength of post cured samples at $100^{\circ} \mathrm{C}$ for 1 hour of $40 \mathrm{Wt} \%$ of cellulose fiber and $60 \mathrm{Wt} \%$ of resin sample had increased with 10.81\%,35 Wt\% E-glass fiber , $5 \mathrm{Wt} \%$ of Cellulose fiber and $60 \%$ of resin sample had increased with $8.69 \%, 20 \mathrm{Wt} \%$ E-glass fiber, $20 \mathrm{Wt} \%$ of Cellulose fiber and $60 \%$ of resin sample had increased with $7.27 \%, 5 \mathrm{Wt} \%$ E-glass fiber, $35 \mathrm{Wt} \%$ of Cellulose fiber and $60 \%$ of resin sample had increased with $14.63 \%$, when compared with, samples without post curing.

- The Hardness of post cured samples at $100^{\circ} \mathrm{C}$ for 1 hour of $40 \mathrm{Wt} \%$ of cellulose fiber and $60 \mathrm{Wt} \%$ of resin sample had increased with $10.86 \%, 35 \mathrm{Wt} \%$ E-glass fiber , $5 \mathrm{Wt} \%$ of Cellulose fiber and $60 \%$ of resin sample had increased with $16.17 \%, 20 \mathrm{Wt} \% \mathrm{E}$ glass fiber, $20 \mathrm{Wt} \%$ of Cellulose fiber and $60 \%$ of resin sample had increased with $14.54 \%, 5 \mathrm{Wt} \%$ E-glass fiber, $35 \mathrm{Wt} \%$ of Cellulose fiber and $60 \%$ of resin sample had increased with $12.22 \%$, when compared with, samples without post curing.

Hence the post curing of the samples only with natural fibre has more promising results compared with synthetic fibre. The synthetic fibres get wrinkled due to post curing were as no such visuals in the natural fibres.

\section{References}

1. Ray B. C. and Rathore D. “ Durability and integrity studies of environmentally conditioned interfaces in fibrous polymeric composites"Critical concepts and comments Adv. Colloid Interface Sci. 209 68-83(2014).

2. Aruniit A, Kers J., Krumme A, Poltimäe T. and Tall K. "Preliminary Study of the Influence of Post Curing Parameters to the Particle Reinforced Composite's Mechanical and Physical Properties"Mater. Sci. 18 256-61(2012).

3. Cagri Uzay "Effect of post-curing heat treatment on mechanical properties of fibrereinforced polymer (FRP) composites" Materials Testing downloaded from www.hanser-elibrary.com by Hanser - Library on April 4, (2017).

4. J. R. Tarpani, O. Maluf, M. Cristina, A. Gatti "Charpy impact toughness of conventional and advanced composite laminates for aircraft construction", Materials Research 12, No. 4, pp. 395-403 DOI:10.1590/S1516-14392009000400004.(2009) 
5. S. W. Hong, S. S. Ahn, H. Li, J. K. Kim, S. J. Ko, J. M. Koo, C. S. Seok "Charpy impact fracture characteristics of CFRP composite materials according to variations of fibrearray direction and temperature", International Journal of Precision Engineering and Manufacturing 14, No. 2, pp. 253-258 DOI:10.1007/s12541-013-0035-9.(2013)

6. D. G. Gonzalez, M. R. Millan, A. Rusinek, A. Arias: "Low temperature effect on impact energy absorption capability of PEEK composites",Composite Structures 134, pp. 440-449 DOI:10.1016/j.compstruct.2015.08.090.(2015)

7. M. Aktaş, R. Karakuzu "Determination of mechanical properties of glass-epoxy composites in high temperatures", Polymer Composites 30, pp. 1437-1441 DOI:10.1002/pc.20708.(2009)

8. S. Cao, Z. Wu, X. Wang "Tensile properties of CFRP and hybrid FRP composites at elevated temperatures", Journal of Composite Materials43, No. 4, pp. 315-330 DOI:10.1177/0021998308099224.(2009)

9. M. G. Kim, S. G. Kang, C. G. Kim, C. W. Kong "Tensile properties of carbon fibre composites with different resin compositions at cryogenic temperatures", Advanced Composite Materials19, pp. 63-77 DOI:10.1163/156855109X434838.(2010)

10. Y. Cao, J. Cameron "The effect of curing conditions on the properties of silica modified glass fibre reinforced epoxy composite", Journal of Reinforced Plastics and Composites26, No. 1, pp. 41-50 DOI:10.1177/0731684407069950.(2007)

11. S. C. Joshi, Y. C. Lam, U. W. Tun "Improved cure optimization in pultrusion with pre-heating and die-cooler temperature", Composites: Part A 34, pp. 1151-1159 DOI:10.1016/j.compositesa.2003.08.003.(2003)

12. A. Aruniit, J. Kers, A. Krumme, T. Poltimae, K. Tall "Preliminary study of the influence of post curing parameters to the particle reinforced composite's mechanical and physical properties", Materials Science (Medžiagotyra) 18, No. 3, pp. 256-261 DOI:10.5755/j01.ms.18.3.2435.(2012)

13. V. A. A. Chetti, R. L. Macchi, M. E. Iglesias "Effect of post-curing treatment on mechanical properties of composite resins", Acta Odontologica Latinoamericana 27, No. 2, pp. 72-76 DOI:10.1590/S1852-48342014000200005.(2014)

14. V. Hiremath, M. Singha, D. K. Shukla "Effect of post curing temperature on viscoelastic and flexural properties of epoxy/alumina polymer nanocomposites", Procedia Engineering97, pp. 479-487 DOI:10.1016/j.proeng.2014.12.272.(2014)

15. D. S. Kumar, M. J. Shukla, K. K. Mahato, D. K. Rathore, R. K. Prusty, B. C. Ray, "Effect of post-curing on thermal and mechanical behavior of GFRP composites", Materials Science and Engineering 75, pp. 1-6 DOI:10.1088/1757899X/75/1/012012.(2015)

16. Manjunath Shettar, Vithal Rao Chauhan "Investigation On Mechanical Properties Of E- Glass, Epoxy Resin With AsbestosFilled /Hybrid Composites" Global Journal Of Engineering Science And Research Management Issn: 2349-4506 February, (2015).

17. Vithal Rao Chavan "Effect Of The Tribological Behaviour Of Hematite Filled Hybrid Composites - A Taguchi Approach" International Journal of Engineering Research and Advanced Technology Special Volume. 02 Issue.01, ISSN: 2454-6135 May (2016). 